\title{
Com a palavra as mães: uma compreensão da forma e do significado da ocupação de cuidar de recém nascidos pré-termos no método canguru
}

\section{A word with mother: understanding the form and meaning of occupancy of kangaroo care in method}

\author{
Con la palabra las madres: una comprensión de la forma y del significado de la \\ ocupación de cuidar de recién nacidos en pre-términos en el método canguro
}

\author{
Recebido: 16/05/2017 \\ Aprovado: 11/08/2017 \\ Publicado:30/03/2018
}

\author{
Rafaela Freires do Carmo ${ }^{1}$ \\ Victor Augusto Cavaleiro Corrêa ${ }^{2}$
}

O objetivo desta pesquisa foi compreender a forma e o significado da ocupação de mães de recém-nascidos que se encontravam na segunda etapa do Método Canguru. 0 estudo consistiu em uma pesquisa qualitativa de caráter exploratório e descritivo. Foi desenvolvida em uma Unidade de Terapia Intensiva Neonatal Canguru de um Hospital público de referência na assistência materno infantil na Região Norte do Brasil. Participaram da pesquisa dez mães de recém-nascidos que se encontravam na segunda etapa do Método Canguru, sendo aplicada uma entrevista semiestruturada e a análise de conteúdo temática como estratégia de tratar os dados. Os resultados foram agrupados em duas categorias: 1) Sobre a forma ocupacional: como se apresentam as Atividades da Vida Diária (AVD'S) de mães em uma enfermaria Canguru; 2) Sobre o significado ocupacional de cuidar de recém-nascidos pré termos em uma enfermaria Canguru.A pesquisa possibilitou compreender os medos, as dúvidas, as expectativas, os desejos referentes à ocupação de cuidar, revelando como se apresentam os fazeres diários nestas condições. Possibilitou a compreensão da forma e do significado ocupacional de ser mãe de crianças prematuras e que se encontravam em uma enfermaria Canguru.

Descritores: Mães; Método Canguru; Terapia Ocupacional.

The objective of this research was to understand the form and meaning of the occupation of mothers of newborns who were in the second stage of the Kangaroo Method. The study consisted of a qualitative exploratory and descriptive research. It was developed in a Kangaroo Neonatal Intensive Care Unit of a public reference hospital in maternal and childcare in the Northern Region of Brazil. Ten mothers of newborns in the second stage of the Kangaroo Method participated in the study. Semi-structured interviews were conducted and thematic content analysis was used as a data-processing strategy. The results were grouped into two categories: 1) On the occupational form: how the Activities of Daily Living (ADLs) of mothers in a Kangaroo ward take place; 2) On the occupational meaning of caring for preterm newborns in a Kangaroo ward. The research made it possible to understand the fears, doubts, expectations, and desires related to the occupation of caring, revealing how the daily activities occur in these conditions. It made it possible to understand the occupational form and meaning of being mothers of premature children and being in a Kangaroo ward.

Descriptors: Mothers; Kangaroo Mother Care Method; Occupational therapy.

El objetivo de ésta investigación fue comprender la forma y el significado de la ocupación de madres de recién nacidos que se encontraban en la segunda etapa del Método Canguro. El estudio consistió en una investigación cualitativa de carácter exploratorio y descriptivo. Fue desarrollada en una Unidad de Terapia Intensiva Neonatal Canguro de un Hospital público de referencia en la asistencia materno infantil en la Región Norte del Brasil. Participaron de la investigación diez madres de recién nacidos que se encontraban en la segunda etapa del Método Canguro, siendo aplicada una entrevista semi-estructurada y el análisis de contenido temático como estrategia de tratar los datos. Los resultados fueron agrupados en dos categorías: 1) Sobre la forma ocupacional: cómo se presentan las Actividades de la Vida Diaria (AVD'S) de madres en una enfermería Canguro; 2) Sobre el significado ocupacional de cuidar de recién nacidos pre-término en una enfermería Canguro. La investigación posibilitó comprender los miedos, las dudas, las expectativas, los deseos referentes a la ocupación de cuidar, revelando cómo se presentan los quehaceres diarios en éstas condiciones. Posibilitó la comprensión de la forma y del significado ocupacional de ser madre de niños prematuros que se encontraban en una enfermería Canguro.

Descriptores: Madres; Método madre canguro; Terapia ocupacional.

Terapeuta ocupacional, Universidade do Estado do Pará (UEPA), Belém, PA, Brasil. ORCID: 0000-0001-6602-269X E-mail: rafa_freire3@yahoo.com.br

${ }^{2}$ Terapeuta Ocupacional. Mestre em Psicologia. Doutor em Doenças Tropicais. Docente da Faculdade de Fisioterapia e Terapia Ocupacional da UFPA, Belém, PA, Brasil. ORCID: 0000-0003-0133-7927 E-mail: victorcavaleiro@ gmail.com 


\section{INTRODUÇÃO}

A maternidade é abordada enquanto momento de vinculação mãe-bebê, que inicia no desejo de gerar um filho, passando pelo vínculo intrauterino, pelo desenvolvimento e demais fases do crescimento e desenvolvimento de uma criança.

A concepção e a escolha de um casal ao decidir gerar um filho, torna-os suscetíveis a responsabilidade para fazer com que o bebê venha com saúde em todos os aspectos. Gestar de uma criança pode estar associado a manifestações de ansiedade.

Para os pais, muitas vezes, situações como ter um bebê que não se aproxima das características esperadas e/ou idealizadas ou que corre risco de vida, podem ser geradoras de dúvidas acerca da sobrevivência da criança. Pode, muitas vezes, estar associado a sentimentos de incapacidade e a possibilidade de uso de equipamentos ${ }^{1}$, preocupações quanto a socialização ${ }^{2}$, fragilidade nos pais, culpa e medo $^{3}$, possíveis dificuldades na acessibilidade $^{4}$, atraso e/ou déficit no desenvolvimento ${ }^{5,6}$ podendo alterar as relações com o meio e com as ocupações diárias ${ }^{7,8}$.

O Ministério da Saúde brasileiro lançou, em 5 de julho de 2000, a Norma de Atenção Humanizada ao Recém-nascido de Baixo Peso - Projeto Mãe Canguru, que ficou difundido como Método Mãe-Canguru ${ }^{9-11}$. Essa norma, atualizada posteriormente pela Portaria $\mathrm{n}^{\mathrm{o}}$ 1.683 de 12 de julho de 2007, contém as informações necessárias à aplicação das três etapas do MC, em que constam a populaçãoalvo, os recursos necessários para a adoção do $\mathrm{MC}$, as normas gerais e as vantagens para a promoção da saúde do RN de baixo peso ${ }^{12}$.

O MC é um modelo de assistência perinatal voltado para o cuidado humanizado. Consiste em promover, a partir da posição canguru, o contato pele a pele entre mãe/pai/familiares e o bebê de baixo peso, de forma gradual, possibilitando maior vínculo afetivo, estabilidade de temperatura do corpo da criança, estímulo à amamentação e ao desenvolvimento do recém-nascido, além de menor tempo de internação, diminuição do choro e mais segurança e envolvimento dos familiares nos cuidados com o bebê ${ }^{12}$.

A segunda etapa do método exige estabilidade clínica da criança, ganho de peso regular, segurança materna, interesse e disponibilidade da mãe em permanecer com a criança o maior tempo desejado e possível. Os benefícios do método incluem redução da morbidade e do período de internação dos bebês, melhoria na incidência e duração da amamentação e contribui para o senso de competência dos pais ${ }^{12}$. Todos esses fatores contribuem para que o bebê passe a mamar com mais frequência e ganhe peso mais rápido, reduzindo $o$ estresse $e$, consequentemente, minimizando 0 gasto energético e calórico ${ }^{13}$.

Segundo Riego ${ }^{14}$, cada indivíduo é moldado pelo ambiente interno (físico, mental e intelectual), pelo espaço físico ambiental (casa, escola ou trabalho), pelas regras que nos condicionam (fatores legais e culturais), e pela interação do ambiente social (família e amigos). Assim, o indivíduo é moldado pelo ambiente que é experienciado. No caso desta pesquisa, a ocupação de ser mãe pode ser modificada pelo espaço físico ambiental do hospital. Esta passa a cumprir regras, a experienciar uma rotina hospitalar, um contexto diferenciado, em que são vividas mudanças na interação com o ambiente social. Tais características podem implicar nas ocupações diárias de quem experiência esse contexto.

Quando esse imaginário é de alguma forma, modificado pela situação vivida e, geralmente, é diferente do planejado, seja com o nascimento prematuro do filho ou com a imagem dele vinculada a uma incubadora, o contexto pode começar a alterar a ocupação de ser mãe de um bebê pré-termo.

0 interesse pela pesquisa ancorou-se na importância em compreender o âmbito ocupacional.Entende-se que as ocupações são definidas como as atividades humanas que atendem às necessidades vitais de um indivíduo, e podem dar ou não sentido à vida, constituir uma identidade pessoal, cultural e social ${ }^{15}$.

Compreende-se que a ocupação é fundamental para os seres humanos e é um 
processo dinâmico influenciado por fatores físicos, psíquicos e sociais, de tal forma que seu uso pode favorecer ou não a adaptação ao ambiente ${ }^{14}$. Dessa forma, entende-se que o ser humano exerce várias ocupações e, ao gerar um filho, a mulher, agora também mãe, exercerá uma nova ocupação, ou novas ocupações.

Para Clark e Lawlor ${ }^{15}$, a Ciência da Ocupação aborda a centralidade do engajamento em ocupações e na vida humana, principalmente, como elas se relacionam com a saúde, o bem estar, a participação social e ocupacional. Nesse sentido, as ocupações são ações que constituem a experiência cotidiana, incluem os tipos de atividade intencional que compõe a vida das pessoas, como as atividades de vida diária, atividades interpessoais, atividades físicas, atividades de restauração e as práticas sociais e culturais, entre tantas outras. Nesse campo do conhecimento, ocupação é definida como uma ação que tem uma forma, um sentido e um significado para quem a executa, envolto em um determinado contexto sociocultural.

A forma da ocupação focaliza os aspectos diretamente observáveis, de como as pessoas organizam e desenvolvem suas ações diárias, estão relacionadas ao modo como as ocupações são realizadas e ao como as pessoas preenchem o tempo em um determinado contexto ${ }^{16}$.

O sentido ou a função compreende os caminhos pelos quais a ocupação promove saúde, bem-estar e qualidade de vida e o significado, compreende os sentimentos, as expectativas e a importância da ocupação dentro do contexto de vida e da cultura dos indivíduos ${ }^{15}$.Partindo desses pressupostos, coloca-se como questão de pesquisa: Como se apresentam a forma e o significado das ocupações de mães de recém-nascidos (RN) que se encontravam na segunda etapa do Método Canguru (MC)?

A Terapia Ocupacional é a arte e a ciência de ajudar pessoas a realizarem atividades cotidianas importantes e significativas para sua saúde e bem - estar por meio do engajamento em ocupações valorizadas $^{15,16}$ e uma possibilidade para refletir sobre o entorno social, sobretudo sobre as condições que podem contribuir ou não para a construção de um ambiente saudável ${ }^{17,18}$.

A segunda etapa do método exige disponibilidade da mãe em permanecer com a criança o maior tempo desejado e possível, o contato pele a pele entre mãe e o bebê e envolvimento diário nos cuidados com o bebê, podendo alterar a forma e o significado das ocupações ${ }^{12}$.

Assim, o objetivo desta pesquisa foi compreender a forma e o significado da ocupação de mães de recém-nascidos que se encontravam na segunda etapa do Método Canguru.

\section{MÉTODO}

Trata-se de uma pesquisa qualitativa, exploratória e descritiva.

Segundo Minayo ${ }^{19}$, na pesquisa qualitativa, o pesquisador procura entender os fenômenos, os fatos ou eventos, segundo a perspectiva dos participantes da situação estudada e, a partir disso, situam suas interpretações acerca dos fenômenos abordados. A pesquisa exploratória busca levantar informações sobre um determinado objeto.

A pesquisa foi desenvolvida em uma Unidade de Cuidados Intermediários - UCIN Canguru de um Hospital Público na Região Norte do País.

Participaram da pesquisa 10 mães de recém-nascidos que se encontravam na segunda etapa do Método Canguru no período de agosto e setembro de 2013. Foram utilizados como critérios de inclusão: ser mãe de recém-nascido que se encontrava na segunda etapa do Método Canguru, ser maior de 18 anos e aceitar participar da pesquisa.

A pesquisa foi aprovada pelo Comitê de Ética em Pesquisa (CEP)do Instituto de Ciências da Saúde (ICS) da UFPA, sendo prestados todos os esclarecimentos as mães através de um Termo de Consentimento Livre e Esclarecido - TCLE, em que foram explicados os objetivos e finalidades do estudo, respeitando todos os direitos e deveres segundo a Resolução 466/2012 do Conselho Nacional de Saúde, em que todas 
confirmaram estar cientes e autorizaram a participação na pesquisa.

Num primeiro momento se estabeleceu vínculo com as participantes da pesquisa, bem como o reconhecimento da dinâmica da instituição e da UCIN Canguru e sua equipe, através da observação livre e registro em diário de campo.

Posteriormente, a pesquisa foi aplicada na UCIN Canguru, que atende em média dezesseis mães, de qualquer idade.

0 estudo ocorreu no período de dois meses e consistiu em uma entrevista com as participantes.A entrevista consistiu, primeiramente, na identificação geral das participantes (nome, sexo, idade, estado civil, escolaridade, religião, tempo de permanência na UCIN Canguru) e, posteriormente, dois questionamentos: "Descreva seu dia na enfermaria canguru", com o objetivo de conhecer a forma ocupacional de ser "mãecanguru" e em seguida: "Para você, qual o significado ocupacional em cuidar de um recém-nascido no Método Canguru?".

A entrevista foi gravada, assim como se obteve registro em diário de campo, a fim de complementar a pesquisa, registrando o "cuidar" diário que existia entre a díade mãebebê. Em seguida, essas informações foram utilizadas para análise dos dados da pesquisa.

A análise dos dados foi realizada através da análise de conteúdo temática, a qual consiste em uma metodologia de tratamento de análise de informações constantes de um documento, sob a forma de discursos pronunciados. Visa compreender, criticamente, o sentido manifesto ou oculto das comunicações ${ }^{20}$.

0 processo analítico empregado dentro da análise de conteúdo foi o de análise temática, que consiste em reportar em cada relato de vida as passagens concernentes a tal ou qual tema, comparando depois os conteúdos dessas passagens de um relato a outro, ou seja, a análise temática consiste em descobrir os núcleos de sentido que compõem a comunicação e, cuja frequência de aparição pode significar o objeto analítico escolhido ${ }^{20}$.

Os relatos foram analisados respeitando-se a individualidade e a especificidade de cada participante, porém os seus discursos foram agrupados em categorias, de acordo com os temas que emergiram do discurso das genitoras.

Após a categorização, realizou-se uma nova leitura das entrevistas na íntegra, comparando-as com as unidades temáticas, identificando a possibilidade de descobrir novos temas e a forma de como realizar os agrupamentos das unidades temáticas.

Para se preservar a identidade das participantes da pesquisa, seus nomes foram substituídos por nomes de flores.

\section{RESULTADOS}

Os resultados foram agrupados em duas categorias: 1) Sobre a forma ocupacional: como se apresentam as Atividades da Vida Diária (AVD'S)de mães em uma enfermaria Canguru; 2) Sobre o significado ocupacional de cuidar de recém-nascidos pré termos em uma enfermaria Canguru.

As categorias de análise deste estudo foram construídas tendo como fio condutor a forma e o significado do cuidar num contexto hospitalar e em um enfoque Neonatal.

\section{Sobre a forma ocupacional: como se apresentam as atividades da vida diária (AVD's) de mães em uma enfermaria canguru}

No rol de ocupações das mães da UCIN Canguru, ocorreram modificações nas ocupações, principalmente no que diz respeito a suas atividades da vida diária, repercutindo amplamente na higiene, na alimentação e no sono, em função de contemplar, prioritariamente, as necessidades do filho, principal enfoque da enfermaria.

Notou-se que, por encontrar-se no contexto hospitalar, as mães já eram submetidas às alterações da rotina da enfermaria, contudo ao serem submetidas às etapas que o Método Canguru da segunda etapa, as mães são submetidas a estarem $24 \mathrm{~h}$ no local, sendo responsáveis pelos cuidados básicos diários, estimulações do neurodesenvolvimento, maternagem, entre outros cuidados, conforme os relatos abaixo: "E ele não dorme de madrugada, aí eu geralmente vou dormi umas duas e meia, por que é quando ele mama geralmente uma hora antes da mamada ou meia hora 
antes da mamada, aí eu não durmo por que mal dormi já tá na hora de acordar (...) Pra tomar banho também é muito rápido, por que quando a gente tá no banheiro, já tem gente chamando a gente por que eles tão gritando..." (Cerejeira).

Ocorreram mudanças no ritmo e no tempo dispêndio às demais ocupações dessas mães, bem como uma necessidade de reorganizar a rotina. Verifica-se também um distanciamento e/ou um abandono de ocupações que eram desenvolvidas antes da experiência da hospitalização, ações que se tornaram secundárias por conta da dedicação prestada ao bebê:

"Não, ixi, mas quando, tem a mamada de meia noite, só que ele, às vezes, fica acordado até 3 h acordado, ai eu tenho que ficar com ele no colo, e não é só ele não, é a maioria das crianças aqui, a gente já fica tudo acordada aqui até três horas, dá outra mamada, aí e que eles vão dormi um pouquinho, ai quando a gente acorda já é na mamada das seis, e não dorme direito, resumindo né? a palavra original "não dorme direito", ai tem dias que eles deixam a gente dormi (...)" (Margarida).

Em alguns casos, seus filhos passaram pela Unidade de Terapia Intensiva Neonatal(UTIN) com necessidade de um suporte tecnológico maior para a sobrevivência. Em outros relatos, estas crianças vinham da Unidade Semi-Intensiva, pelo qual o RN encontrava-se um pouco mais estável, mas ainda com necessidades de cuidados complementares após alta da UTIN.

Esta realidade anunciava um cuidar diferenciado e restrito na segunda etapa, em um serviço hospitalar com infraestrutura física e material para acolher mãe e filho com repouso e permanência no mesmo ambiente durante 24 horas por dia até a alta hospitalar.

Desta forma, quando a criança atingia o peso ideal em nutrição enteral plena, as crianças passavam para outra etapa do método. Essa nova situação era vivenciada, muitas vezes, de maneira positiva, pois sair da Unidade Neonatal significava melhora na evolução clínica, esperança e novas responsabilidades, que eram, exclusivamente, vividas pela mãe e/ou substituto que ficava responsável pelo bebê 24 horas na UCINCa.

"Assim, por que quando eu tava lá em cima, é diferente né?, por que a gente veio pra cá, só que aí não é a gente que tá cuidando né, e não cuidam como a gente né,(...), ai eu queria descer pra cá justamente por isso, por que eu ia aprender a cuidar dele, por que ia ter que aprender né, ai eu que ia cuidar dele aqui, ai se acontecesse alguma coisa com ele já era minha culpa né não era deles, por que uma vez eu perguntei lá pra menina por que que não tavam trocando, por que ela falou que lá era mais medicação, eles não sabem lhe dá com criança prematura, foi isso que ela me respondeu (risos), ai aqui já é diferente..." (Cerejeira).

Outras participantes relataram como positivo a aproximação entre mãe e bebê que o método Canguru proporciona.

"Ah, cuidar dele é uma maravilha, perto do que eu passava lá no isolamento que eu não podia nem meter a mão lá dentro da Isolette, (...), eu pego ele, carrego ele, dô banho nele, eu merma dou banho nele, eu que dou a comidinha dele, às vezes, eu tiro do meu seio pra dar pra ele, que é o mermo que tá em casa, ai é bom muito bom, ainda mais que foi a minha primeira gravidez, é uma experiência muito boa que a gente passa. Por que graças a Deus que a gente pode ficar aqui olhando ele e se a gente não pudesse, como é que ia ser, fico pensando né, hoje eu já sei fazer tudo com ele, até o banho (...)" (Margarida).

Nos relatos, as participantes da pesquisa revelaram que se ocupar neste contexto pode significar algo que varia entre os extremos bom e ruim. Relataram ser um local diferente, com regras e deveres que não podem ser rompidos e que implicam em mudanças no rol e nos ritmos das ocupações de cada genitora.

Também, percebeu-se que nenhuma mãe participante desta pesquisa era oriunda da região metropolitana ou capital do Estado, ou seja, todas estavam longe de seus municípios de origem, e muitas vezes, devido à condição socioeconômica e geográfica não conseguiam ter o apoio de sua família através das visitas, que mesmo restritas e com horários programados são permitidas.

Muitas vezes, os familiares só conseguem visitá-las uma vez na semana, ou a cada quinze dias, uma vez no mês, ou nunca as visitaram, devido as condições socioeconômicas, longas distâncias e de infraestrutura para se manterem na capital. Este fator, somado a uma rotina intensa de horários e ocupações voltadas ao cuidado da criança, podem intensificar sentimentos e sensações de ausências, abandono ou adiamento de outros desejos e preferências ocupacionais.

"Banho dá pra tomar, a comida tem que comer ligeiro e o banho também, as canela chega tão cinzenta (risos). Eu gosto daqui por que as minina tão sendo bem cuidada, tomando medicamento, graças a Deus, se tivesse lá em casa tava pior né, mas por outro lado é muito estresse, muito cansativo, cuidar de duas então, a rotina cansa, é só ficar a maior parte do tempo sentada, deitada, sem 
sair meno pra andar lá fora, ai as meninas começam a chorar, ai também saudade de casa, das pessoas, é isso né" (Orquídea).

O apoio recebido da família é um elemento estruturador importante para estas genitoras para melhor lidarem com a situação e buscar forças perante os desafios impostos no cuidado diário:

“(..) é por que aqui a gente somo uma família, se acontecer alguma coisa com alguém daqui a gente fica tudo preocupado, triste, por que não quer que isso aconteça com nenhum deles, nem com o nosso nem com eles" (Tulipa).

"(...) é bom demais, eu vou sentir falta daqui, das enfermeiras na hora do remédio, e da mamada, "mãezinha chegou", "mãezinha o remédio", e lá em casa não, lá em casa eu vou ter que ser bem mais esperta, relógio despertou já tenho que levantar, tenho que botar pra despertar meia hora antes que é pra tá com o olho bem aberto (risos)" (Lavanda).

Nos relatos a seguir, verifica-se uma experiência pessoal através da percepção da forma ocupacional e expressão das emoções e a vontade de retorno ao lar:

"(...)Eu quero ir pra minha casa, ir pra minha cama, comer a minha comida, por que eu não aguento mais. Mas ainda dá um friozinho de barriga ir pra casa e ficar com eles sozinha né, por que aqui a gente tem uma ajudinha de vez em quando e em casa não né." (Azaléia).

\section{Sobre o significado ocupacional de cuidar de recém-nascidos pré termos em uma enfermaria canguru}

A percepção do cuidar é percebida nas falas a seguir:

"Cuidar dele é bom, mas um pouco cansativo, preocupante, por que a gente não sabe, a gente fica, ai será que vai ganhar peso, será que não, a gente tem que ver tudo direitinho, não deixa chorar, ai tem que botar pra dormir, ai põe no canguru, isso tudo preocupada pra vê se ele ganha um pesinho de tarde, essa é a maior preocupação(...)" (Tulipa).

Na fala a seguir a questão da díade mãebebê se mostra:

Eu tenho medo da saúde dela, por que quando ela tava na UTI, como ela passou muito tempo intubada, ai sempre fica assim uma sequela ne, por que como a doutora falou assim como o oxigênio ajuda a criança a sobreviver ele também prejudica bastante, então a minha única preocupação com ela, é assim de um dia ela ficar muito cansadinha, que nem aconteceu com a colega, ai é isso, por que ela passou muito tempo na UTI, quase dois meses, faltou poucos dias pra dois meses então eu tenho sim muita preocupação, nada que um cuidado não possa resolver né, eu já cuidei muito do filho dos outros, de outras crianças e o que eu aprendi com eles eu quero também fazer com ela né, cuidar dela, da saúde dela, é isso que eu espero, não quero ver meu bebê dodói (Jasmim).

Através de relatos diretos como por atitudes demonstradas pelas genitoras como dedicação, esforço, alegria pelos mínimos ganhos clínicos, bem como, expressão facial, em que a satisfação e a felicidade evidenciavam a realização desta ocupação sem obrigatoriedade:

"No início eu sentia muito medo de cuidar dele, por que a primeira vez que eu vi ele na UCI junto das outras crianças em estado crítico eu passei muito mal sabe, a pressão subiu e eu chorei muito, desse dia eu não quis mais vê-lo, ai quando ele desceu pra cá, ele era muito pequeno, eu tinha medo de segurar, de mexer sabe. Bom, antes era ela levinho né, pesava quase nada, agora ele tá com 1.360g, ai fico olhando o dia inteirinho pra ele, cuidando, por que ele tá bem melhor agora, tenho segurança de trocar ele, de dá banho, tranquilo. Pra mim cuidar dele é tudo" (Bergamota).

A motivação e interesse pessoal, que permite algum desafio para quem a desenvolve e que, quando alcançada transforma-se em satisfação pessoal.

0 significado dessas experiências também pode ser influenciado por condições inatas da pessoa que a impulsionam a certos estilos de ocupações, como exemplo as mães de "primeira viajem" e mães que já tem outros filhos, mas nunca tiveram a experiência de ser mãe de um prematuro, logo esse cuidar diferenciado alternam outros significados:

"Cuidar delas tem hora que é bom, mas tem hora que é ruim (risos), o bom é que a gente aprende a cuidar, mas tem hora que falta paciência que se elas fossem maior dava umas palmada certeira na bunda (risos), e a cada dia a gente aprende uma coisa nova, tivesse em casa eu tava frita, eu já cuidei muito de criança, mas prematuro é a primeira vez, tivesse ido pra casa diretamente eu não sei nem o que tinha acontecido por que é muito diferente de cuidar do normal ixi, se é complicado cuidar de bebê, imagine prematuro" (Orquídea).

"(...)Cuidar do bebê prematuro assim é muito difícil né pra quem não tá acostumado, por que o de nove meses é diferente tu dá banho normal, cuida dele, e no outro a gente tem medo até de gripar por que o nariz é demais pequeno, ela não consegue nem respirar quando tá sujinho o nariz dela, diferente, complicado, mas a gente aprende, a gente aprende a lhe dá com a situação" (Lírio).

\section{DISCUSSÃO}

A forma da ocupação é um conjunto de aspectos físicos e socioculturais externos que se apresentam como um acontecimento na vida da pessoa. Estruturando-se de maneira 
singular, em decorrência das habilidades e características próprias de cada pessoa, a forma ocupacional se encontra em contínuo desenvolvimento e mudança ${ }^{16}$.

Está relacionada aos aspectos diretamente observáveis, ou seja, o que as pessoas fazem, como o fazem (relação a tempo, espaço e desempenho) e em quais circunstâncias ${ }^{16}$.

São inúmeros os fatores que podem influenciar a forma ocupacional, tais como vivência de uma nova rotina diária, saudades do lar e familiares, expectativas construídas acerca do prognóstico do bebê e a espiritualidade, os quais são determinados por características e valores pessoais.

0 reconhecimento do ambiente no condicionamento da experiência humana está relacionado à compreensão que uma pessoa tem deste, não podendo ser alcançada sem uma apreciação do contexto ambiental ${ }^{21}$. As intervenções que tiram uma pessoa do lugar por exemplo, aqueles que envolvem a reconfiguração de residência ou aqueles que ocorrem em um ambiente hospitalar, clínico ou de reabilitação - estão invariavelmente comprometidos, porque a organização da pessoa é, necessariamente, modificada para lidar com a adaptação de um ambiente novo e desconhecido ${ }^{21}$.

A sensação de uma pessoa estar em um determinado lugar é um fenômeno complexo e dinâmico. Durante toda a trajetória de vida, à medida que se muda de um local para outro, se esta constantemente criando e recriando o lugar como um componente de identidade pessoal. Alguns destes são significados individuais e bastante pessoais, eles podem expressar uma sensação de afinidade com os locais em que aconteceram eventos-chave na vida $^{21}$.

o reconhecimento do tempo na experiência humana permite compreender o estar no lugar mais que uma ocupação física do espaço, mas também como o uso das habilidades de orientação e o desenvolvimento de afiliação emocional com determinados lugares ${ }^{21}$.

Outros sentimentos relacionados com o espaço refletem significados compartilhados, elas se originam da habitação comum do espaço ${ }^{21}$.

A expressão mais intensa de estar no lugar envolve, caracteristicamente, a relação com o lar - usualmente, embora não de modo invariável, a casa em que se mora ${ }^{21}$.

Estar no lugar e na relação consigo mesmo é um fenômeno dinâmico, durante toda a trajetória da vida, à medida que se muda de um local para o outro, se cria e recria o lugar, colocando também as significações pessoais, pois para cada mãe a UCIN Canguru significará algo para o resto de suas vidas, sendo positivo ou negativo.

O lar é o local de privacidade, segurança e seguridade. Com frequência o lar é o fulcro espacial de nossa vida, um lugar de conforto e centralização, um lugar do qual nos aventuramos para um mundo externo, potencialmente hostil, além da casa e para o qual se retorna em busca de abrigo ${ }^{21}$.

A ocupação é considerada um aspecto central da experiência humana que cumpre as necessidades básicas essenciais para a sobrevivência, fornecendo às pessoas mecanismos para exercitar e desenvolver suas capacidades tanto biológicas, sociais, culturais, e outras.

Assim, notou-se que se ocupar de ser mãe de um RN na UCI Canguru, pode significar a ocorrência de medos, desejos, emoções, (re)significações peculiares desta experiência e, também a presença de esperança e de expectativas quanto ao retorno ao lar, com seu filho saudável.

O lar é um lugar de liberdade, um local onde podemos relaxar, e sermos nós mesmos. o lar é um repositório dos itens que acumulamos que catalogam nossa história e define quem nós somos ${ }^{21}$.

Os relatos das participantes do estudo possibilitou o conhecimento dos vários fatores que influenciam na organização da forma da ocupação no cuidar maternal em um contexto hospitalar.

Dentre estas, destacam-se as questões socioeconômicas, culturais, a presença de estímulos ou a falta deles, como poder contar com apoio de outras pessoas importantes para dividir as funções, o tratamento de pessoas com o próximo, sendo o familiar ou a 
equipe de saúde que nesse momento é primordial, pois no contexto hospitalar, é a que se encontra mais próximo e em maior parte do tempo com essas mães.

A readaptação que muitas delas tiveram que fazer para se adequar de alguma forma a uma nova condição de estarem em um ambiente não comum até a alta hospitalar de seu bebê, e assim exercerem a participação ocupacional totalmente alterado pelos deveres e horários "impostos" por uma rotina por vezes cansativa e difícil.

Nesse contexto o foco são seus bebês, que tão importante quanto elas, necessitam de seu bem estar pleno para sua sobrevivência.

Geralmente, cuidar e criar filhos, são condições essenciais para a continuidade da vida, são ocupações comuns, embora complexas. Essas ocupações são profundamente significativas, intensamente pessoais, francamente compartilhadas e socialmente construídas ${ }^{22}$.

0 cuidado caracteriza-se como um fenômeno vital na vida dos seres humanos, pautado na própria identidade humana de coexistência e inter-relação, configurando-se numa relação de troca e empatia. É um modo de ser e estar com o outro que se refere, principalmente, às questões especiais da vida das pessoas, como a preservação e a recuperação da saúde, o nascimento e até mesmo a morte 23,24 .

Nesta pesquisa, a ocupação "cuidar" desses recém-nascidos de baixo ou muito baixo peso, significava desde o prazer de cuidar de uma vida tão pequena e frágil, mas também com a convivência com o medo de uma possível perda, morte, às vezes inerente à condição clínica, independente dos cuidados prestados pelas genitoras.

0 cuidado pode ser compreendido como solicitude, dedicação e inquietação pelo outro; e implica conhecimentos, comportamentos, valores, habilidades e atitudes do cuidador, o qual é influenciado por suas vivências sociais, culturais e psíquicas ${ }^{23}$.

A família pode ser compreendida como a unidade primária de cuidado, já que por meio das experiências nela vivenciadas criam-se e cultivam-se valores e crenças que contribuem para a formação de seus membros, os quais interagem entre si, apoiando-se e trocando experiências para, juntos, buscarem e somarem esforços para superar limites e solucionar problemas ${ }^{23}$.

Destaca-se também que, a genitora pode evocar sentimentos de ansiedade, medo e insegurança, pois a condição de ser mãe de um prematuro nem sempre é assimilada de maneira rápida, e esses sentimentos a deixam mais frágeis e suscetíveis, por isso o apoio de familiares traz não só um grande diferencial auxiliando este cuidar, mas também maior segurança e amparo a essa genitora que permanece muito tempo em uma rotina hospitalar atípica.

Sob o ponto de vista da criança recémnascida, sabe-se que ela necessita de contato afetivo contínuo, advindo de uma figura constante - comumente a sua mãe - com a qual poderá estabelecer relações de apego que venham a assegurar e favorecer seu desenvolvimento biopsicoafetivo ${ }^{24}$.

O comportamento de apego (afeto) é visto como aquilo que ocorre quando são ativados certos sistemas comportamentais. Acredita-se que os próprios sistemas comportamentais se desenvolvem no bebê como resultado de sua interação com seu meio ambiente de adaptabilidade evolutiva e, em especial, de sua interação com a principal figura nesse meio ambiente, ou seja, a mãe ${ }^{24}$.

0 que no contexto da prematuridade pode não ocorrer, pois acontece uma separação necessária para a sobrevivência do bebê, mas ao mesmo tempo prejudicial no que tange o relacionamento afetivo da díade mãebebê.

Cada família é única e vivencia este processo de maneira própria. Portanto, é importante conhecê-la, compreender seu comportamento, seus sentimentos e os significados dessa vivência, e a partir do conhecimento dos contextos familiares específicos de cada criança nascida prematura, buscar promover uma assistência centrada em suas necessidades individuais, reconhecendo-as enquanto sujeitos que mantém relações com seu cenário social e com seu grupo familiar ${ }^{24}$.

0 nascimento de uma criança e sua inserção no contexto familiar exigem 
adaptações e mudanças na forma de participação ocupacional de cada membro da família, os quais buscam atender as demandas de afeto e cuidado do recém-nascido (RN) e organizar a nova dinâmica familiar. Entretanto, quando o nascimento se dá prematuramente, associado ao baixo peso ao nascer, há a necessidade de internação do bebê, alterando a dinâmica da família de forma inesperada.

Sob o ponto de vista da mulher que gera uma criança, o momento inicial após o parto é considerado precursor do apego, a primeira oportunidade da mãe de ser sensibilizada pelo seu bebê e principiar o exercício social da maternagem. Para a genitora, este estreitamento serve, por assim dizer, como um arrematamento para o longo percurso gestacional recém-finalizado ${ }^{24}$.

Os bebês, quando nascem, já estão equipados com certo número de sistemas comportamentais, prontos para serem ativados por estímulos, como o contato pelea-pele (toque), olho-no-olho, a fala e/ou a emanação de sons, o odor (cheiros) e a amamentação 24 .

Alguns dos procedimentos neonatais são essenciais para a vitalidade do recémnascido, mas a separação mãe-bebê pode desencadear prejuízo ao início do apego e deixar escapar um momento essencial para o estabelecimento do vínculo ${ }^{24}$.

Dentre os resultados da pesquisa, foi perceptível nos relatos das mães, a associação da ocupação do cuidar não como uma obrigação, apesar de terem que seguir um rol de ocupações focado neles.

Mas mesmo com esse cuidar diferenciado e por vezes transpassado de sentimentos como medo do prognóstico da criança, também era associado a pequenos prazeres diários e conquistas que vão desde um pequeno ganho de peso, até sua possível alta hospitalar.

Verificou-se a angústia e a esperança das participantes em conseguir que todo o esforço dedicado a suas crianças seja recompensado por meio da melhora clínica e desenvolvimento de seu bebê. Estas expectativas foram destacadas como uma das principais condições motivadores da ocupação de cuidar.

Os relatos revelaram que a reformulação de planos de vida acarretou ganhos no comportamento e/ou postura com a família, melhorando relações, as responsabilidades, a dedicação, e uma melhor compreensão de seu papel social e, especialmente, pessoal e ocupacional.

Algumas mães descreveram esta situação como um aprendizado singular diretamente ligado ao nascimento de seu bebê.

Foi importante perceber que, em meio às dificuldades percebidas no cotidiano $\mathrm{e}$ relatadas ao longo desta pesquisa, as mães assumiram que mesmo possuindo experiência de já ter um filho ou mais de um, cuidar de um prematuro foi uma situação nova, diferente, desafiadora e um aprendizado, uma lição de vida e pela vida.

Por esse motivo, a pesquisa permitiu a compreensão dos inúmeros sentimentos que envolvem este público, pois apesar de muitas genitoras relatarem perceber a responsabilidade do cuidado como um prazer, também revelaram estresse em determinados momentos, devido à rotina intensa.

Isto configurou uma oscilação na forma de ver e/ou encarar esta condição ocupacional, compreendida pelo excesso de zelo, de responsabilidade, de tarefas assumidas, e os diferentes papéis que devem ser desempenhados diante desta realidade. Um rol de ocupações permeado de dúvidas, medos, descobertas, aprendizados, conquistas, entre outras situações experienciadas.

A partir dos relatos, acredita-se que essas mães conseguiram organizar a forma de sua ocupação de cuidar, frente a cada situação demandada pelos bebês, dividindo-se entre atender as necessidades destes e seus próprios fazeres. Estes fatores apresentaramse de suma importância para a compreensão do significado atribuído a esta ocupação.

\section{CONCLUSÃO}

Compreender como se apresentam as ocupações de cuidar de um filho prematuro e, por vezes, também de baixo peso, os 
sentimentos envolvidos, o tempo despendido, entre outros aspectos, apresentou-se como um rico instrumento de conhecimento capaz de contribuir com as pessoas envolvidas neste contexto.As genitoras dessas crianças, ocupam-se, diariamente, pela (sobre)vivência dos seus recém-nascidos.

0 momento da entrevista funcionou também como um espaço de escuta e acolhimento, um meio à comunicação no qual se viabilizou estratégias de apoio e assistência neste processo tão delicado, face à diversidade de experiências trazidas, colocando-as em um contexto em que se buscava, acima de tudo, valorizar e conhecer seus mais íntimos sentimentos em relação aos fazeres naquele momento de vida, deixandoas que se expressassem, reconhecendo a existência da singularidade de cada caso.

A pesquisa serviu como subsídio para entender as formas e significados ocupacionais desta ocupação tão importante. Compreender as necessidades das mães tornou mais completa a assistência oferecida às crianças, por acolher e instruir quem está diariamente mais próximo das mesmas.

Conhecer o outro e buscar entender as diversas formas e significados atribuídos ao fazer, foram conquistas que a pesquisa possibilitou.

Se pode disponibilizar assistência terapêutica ocupacional ancorada e atenta as demandas ocupacionais resultantes do processo de viver e das implicações passiveis de serem vividas em contextos hospitalares.

\section{REFERÊNCIAS}

1. Volpini M, Brandão MB, Pereira LÁR, Mancini MC, Assis MG. Mobilidade sobre rodas: a percepção de pais de crianças com paralisia cerebral. Cad Ter Ocup UFSCar. 2013; 21(3): 4718. http://dx.doi.org/10.4322/cto.2013.049

2. Galvão BAP, Veloso MP, Freita LPC, Magalhães LC. Perspectiva dos pais sobre as consequências funcionais do Transtorno do Desenvolvimento da Coordenação (TDC): revisão da literatura. Cad Ter Ocup UFSCar. 2014; 22(1):187-93. http://dx.doi.org/10.4322/cto.2014.020

3. Silva CCB, Ramos LZ. Reações dos familiares frente à descoberta da deficiência dos filhos. Cad Ter Ocup UFSCar. 2014; 22(1): 15-23. http://dx.doi.org/10.4322/cto.2014.003.
4. Rodrigues SM, Aoki M, Oliver FC. Diagnóstico situacional de pessoas com deficiência acompanhadas em terapia ocupacional em uma unidade básica de saúde. Cad Ter Ocup UFSCar. [Internet]. 2015 [citado em 23 jan 2016]; 23(4):781-94. Disponível em: http://www.cadernosdeterapiaocupacional.ufsca r.br/index.php/cadernos/article/view/1352. Doi: http://dx.doi.org/10.4322/0104-

4931.ctoA00713.

5. Garcia NBC, Magalhães LC, Santos JLF. Coordenação fina e escrita de crianças de 6 a 9 anos. Rev Ter Ocup. [Internet]. 2015 [citado em 23 jan 2016]; 26(2):166-75. Disponível em: http://www.revistas.usp.br/rto/article/view/90 029/101711.

Doi:

http://dx.doi.org/10.11606/issn.2238-

6149.v26i2p166-175.

6. Souza AB, Assis SM, Rezende lk, Cymrot. Caracterização do desempenho funcional de indivíduos com síndrome de Down. Rev Ter Ocup. [Internet]. 2015 [citado em 23 jan 2016]; 26(1):102-8. Disponível em: http://www.revistas.usp.br/rto/article/viewFile /62266/96383. Doi: http://dx.doi.org/10.11606/issn.2238-

6149.v26i1p102-108

7. Kramec K, Nascimento GCC. A orientação à família de pessoas com deficiência. Rev Ter Ocup. [Internet]. 2015 [citado em 23 jan 2016]; 26(1):128-35. Disponível em: https://www.revistas.usp.br/rto/article/viewFil e/84459/96385.

DOI: http://dx.doi.org/10.11606/issn.22386149.v26i1p128-135.

8. Burnagui JG, Rosa MP, Nascimento GCC. Autonomia e independência: percepção de adolescentes com deficiência visual e de seus cuidadores. Rev Ter Ocup. [Internet]. 2016 [citado em 23 jan 2016]; 27(1):21-8. Disponível em: http://www.revistas.usp.br/rto/article/view/10 $4407 / 114556$.

Doi: http://dx.doi.org/10.11606/issn.2238-

6149.v27i1p21-28.

9. Toma TS. Método mãe canguru: o papel dos serviços de saúde e das redes familiares no sucesso do programa. Cad Saúde Pública [Internet]. 2003 [citado em 03 nov 2015]; 19 (Sup.2):S233-S42. Disponível em http://www.ibfan.org.br/documentos/outras/M MCttoma2003.pdf.

10. Venancio SLAH. Método mãe canguru: aplicação no Brasil, evidências científicas e impacto sobre o aleitamento materno. J Pediatr. [Internet]. 2004 [citado em 29 set 2015]; 80(5 Supl.):S173-S180. Disponível em: 


\section{Carmo RF, Corrêa VAC}

http://www.scielo.br/pdf/jped/v80n5s0/v80n5 s0a09.

11. Costa R, Monticelli M. Método mãe-canguru. Acta Paul Enferm. 2005; 18(4):427-33.

12. Ministério da Saúde (Br). Atenção humanizada ao recém-nascido de baixo peso: método canguru [Internet]. Brasília, DF: Ministério da Saúde; 2014 [citado em 02 dez 2015]. Disponível em: http://bvsms.saude.gov.br/bvs/publicacoes/aten cao_humanizada_recem_nascido_canguru_1ed.pd. 13. Fundação Santa Casa de Misericórdia do Pará. A Santa Casa [Internet]. Belém, PA: Fundação Santa Casa de Misericórdia do Pará; 2014 [citado em 29 set 2015]. Disponível em: http://www.santacasa.pa.gov.br/?q=node/50.

14. Riego SSD. Terapia ocupacional: del siglo XIX al XXI: historia y concepto de ocupación. Rehabilitación (Madrid). 2005; 39:179-84.

15. Clark F, Lawlor MC, A elaboração e o significado da ciência ocupacional. In: Crepeau EB, Cohn ES, Schell BAB. Terapia ocupacional. 10ed. Rio de Janeiro: Guanabara Koogan; 2011. p. 2-14. 16. Dickie V. O que é ocupação? In: Crepeau, EB, Cohn ES, Schell BAB. Terapia ocupacional. 10ed. Rio de Janeiro: Guanabara Koogan; 2011. p. 15-21. 17. Marcelino JFQ. A diferença no cenário familiar, a inclusão escolar e a terapia ocupacional. Cad Ter Ocup UFSCar. [Internet]. 2013 [citado em 23 jan 2016]; 21(1):187-93. Disponível em: http://www.cadernosdeterapiaocupacional.ufsca r.br/index.php/cadernos/article/view/744/429. Doi: http://dx.doi.org/10.4322/cto.2013.023.

18. Baleotti LR, Omote S. A concepção de deficiência em discussão: ponto de vista de docentes de terapia ocupacional. Cad Ter Ocup UFSCar. [Internet] 2014 [citado em 23 jan 2016]; 22(1):71-8. Disponível em: http://www.cadernosdeterapiaocupacional.ufsca r.br/index.php/cadernos/article/view/586/489. DOI: http://dx.doi.org/10.4322/cto.2014.008.

\section{Terapia Ocupacional e Neonatologia}

19. Minayo MCS. O desafio do conhecimento: pesquisa qualitativa em saúde. São Paulo. Hucitec; 2013.

20. Bardin L. Análise de Conteúdo. Lisboa: Edições 70; 2011.229p.

21. Rowles GD. 0 significado do lugar. In: Crepeau EB, Cohn ES, Schell BAB. Terapia ocupacional. 10ed. Rio de Janeiro: Guanabara Koogan; 2011. p. 81-90.

22. Oliveira AKC, Matsukura TS. Estresse e apoio social em cuidadores de crianças com paralisia cerebral. Cad Ter Ocup UFSCar. [Internet]. 2013 [citado em 23 jan 2016]; 21(3):493-503. Disponível

em:

http://www.cadernosdeterapiaocupacional.ufsca r.br/index.php/cadernos/article/view/909/461. Doi: http://dx.doi.org/10.4322/cto.2013.051.

23. Sassa AH, Marcon SS. Avaliação de famílias de bebês nascidos com muito baixo peso durante $o$ cuidado domiciliar. Texto \& Contexto Enferm. [Internet]. 2013 [citado em 03 nov 2013]; 22(2):442-51. Disponível em: http://www.scielo.br/pdf/tce/v22n2/v22n2a21. pdf

24. Rosa R, Martins FE, Gasperi, BL, Monticelli M, Siebert ERC, Martins NM. Mãe e filho: os primeiros laços de aproximação. Esc Anna Nery Rev Enferm. [Internet]. 2010 [citado em 23 jan 2016]; 14(1):105-12. Disponível em: http://www.scielo.br/pdf/ean/v14n1/v14n1a16 .pdf. Doi: http://dx.doi.org/10.1590/S141481452010000100016

CONTRIBUIÇÕES
Rafaela Freires do Carmo participou do
projeto, análise e discussão dos dados, além da
elaboração e revisão do manuscrito. Victor
Augusto Cavaleiro Corrêa coordenou e
orientou a pesquisa, participando da análise,
discussão e interpretação dos dados, além da
elaboração e revisão do manuscrito.

\footnotetext{
Como citar este artigo (Vancouver)

Carmo RF, Corrêa VAC. Com a palavra as mães: uma compreensão da forma e do significado da ocupação de cuidar de recém nascidos pré-termos no método canguru. REFACS [Internet]. 2018 [citado em inserir dia, mês e ano de acesso];6(1):15-25. Disponível em: inserir link de acesso. DOI: inserir link do DOI.

\section{Como citar este artigo (ABNT)}

CARMO, R. F.; CORREA, V. A. C. Com a palavra as mães: uma compreensão da forma e do significado da ocupação de cuidar de recém nascidos pré-termos no método canguru. REFACS, Uberaba, v. 6, n. 1, p. 15-25, 2018. Disponível em: <inserir link de acesso>. Acesso em: inserir dia, mês e ano de acesso. DOI: inserir link do DOI.

Como citar este artigo (APA)

Carmo, R. F. \& Corrêa, V. A. C. (2018). Com a palavra as mães: uma compreensão da forma e do significado da ocupação de cuidar de recém nascidos pré-termos no método canguru. REFACS, 6(1), 15-25. Recuperado em: inserir dia, mês e ano de acesso de inserir link de acesso. DOI: inserir link do DOI.
} 